\title{
Gender Differences in Health Practices in Middle Adolescent Boys and Girls
}

\section{Robert Scoloveno}

Rutgers, The State University of New Jersey, School of Nursing, 530 Federal Street, Camden, NJ 08102, USA

\begin{abstract}
The purposes of this study are to examine responses to the revised ALP in a sample of urban middle adolescents and to further analyze these responses according to gender. The study of health practices of adolescents has gained increased attention over the past several decades and the knowledge gained from these studies has been vital in promoting health during early, middle, and late adolescents. This descriptive-comparative study is part of a larger research project on health-related outcomes in adolescents. The study focuses on a detailed analysis of one instrument used in the study, the ALP-R2. The final sample of convenience consisted of the 311 participants who completed the instrument packets that included the ALP-R2. An independent t- test determined that adolescent boys $(M=121.02)$ had a higher mean score on the total ALP-R2 than adolescent girls $(M=114.99)$ at a statistically significant level $(t(308)=2.57, p=.01$. The findings of this study demonstrated that adolescent girls practiced fewer health-promoting behaviors than adolescent boys, making them a vulnerable population. Outreach measures by healthcare professionals, especially school nurses and physicians are needed and might best be practiced in school settings that are less threatening environments than offices or clinics. School nurses and physicians, and other healthcare professionals can capitalize on the recommendation that schools are in a unique position to foster healthy eating habits. First and foremost, health care professionals, including nurses and doctors, need to take the leadership in addressing better culturally relevant nutrition among adolescents. Healthcare professionals, specifically school nurses, can work with teachers to put into place comprehensive and grade-related health education curricula whereby students learn about health eating behaviors.
\end{abstract}

\section{Aims and Objectives}

The study of health practices of adolescents has gained increased attention over the past several decades and the knowledge gained from these studies has been vital in promoting health during early, middle, and late adolescents. As might be expected, researchers have used a variety of instruments to study adolescent health behaviors in healthy and clinical samples. The Adolescent Lifestyle Profile (ALP) is a fairly recent addition to the scientific literature [1], so there is limited information about adolescent health promoting lifestyle generated from use of this instrument, especially at the descriptive level. To address this gap in the literature, the purposes of this study are to examine responses to the revised ALP in a sample of urban middle adolescents and to further analyze these responses according to gender. Knowledge gained from this study can be used by health care professionals to promote health according to strengths and weaknesses in adolescent health practices.

\section{Background}

The Health Promotion Model was first introduced over thirty years ago by Pender [2] and has been used worldwide since its inception. The Health Promotion Model has undergone a series of revisions over time. Most recently, Pender, Murdaugh, and Parsons [3] defined health promotion as behaviors that include a healthy lifestyle, motivated by individuals' desire to increase their health potential for productive living and improved health. Pender et al. specifically defined health-promoting lifestyle activities as encompassing health responsibility, physical activity, nutrition, spiritual growth, interpersonal relationships, and stress management. Relevant to this study, in her 1996 revised model, Pender proposed that gender has a direct and indirect effect on health-promoting behaviors, making gender an important variable to examine in terms of health behaviors. The Health Promoting Lifestyle Profile (HPLP) instrument for adults, based on Pender's model, was developed by Walker, Sechrist, and Pender [4] and had 6 subscales (a) self-actualization, (b) health responsibility, (c) exercise, (d) nutrition, (e) interpersonal support, and (f) stress management; the HPLP II currently has subscales measuring (a) physical activity, (b) spiritual growth, (c) health responsibility, (d) nutrition,(e) interpersonal relationships, and (f) stress management [5].The Health Promoting Lifestyle Profile II was adapted for use in adolescents by Hendricks, Pender, and Hendricks [1], and labeled the Adolescent Lifestyle Profile (ALP). The current Adolescent Lifestyle Profile (ALP-R2) measures the frequency of 7 domains of health promoting behaviors (a) health responsibility, (b) physical activity, (c) nutrition, (d) positive life perspective, (e) interpersonal relations, (f) stress management, and (g) spiritual health according to C.S.Hendricks (personal communication, January 26, 2012).

Over time researchers studying health behaviors of adolescents, using Pender's framework, have used the adult version of the HPLP or the HPLP II. Felton, Parsons, and Hassell [6] studied the health behavior of 26 adolescents with a history of abortion matched with 26 never-pregnant adolescents using the HPLP. The researchers reported descriptive statistics of the total instrument for the adolescents with a history of abortion $(M=114.08 ; S D=20.07)$ and for the never-pregnant

"Corresponding Author: Dr. Robert Scoloveno, Rutgers, The State University of New Jersey, School of Nursing, 530 Federal Street, Camden, NJ 08102, USA Tel: 1-856-225-2785; E-mail: rscolove@camden.rutgers.edu

Citation: Scoloveno R (2017) Gender Differences in Health Practices in Middle Adolescent Boys and Girls. Int J Nurs Clin Pract 4: 268. doi: https://doi. org/10.15344/2394-4978/2017/268

Copyright: (c) 2017 Scoloveno. This is an open-access article distributed under the terms of the Creative Commons Attribution License, which permits unrestricted use, distribution, and reproduction in any medium, provided the original author and source are credited. 
adolescents $(M=120.50 ; S D=17.15)$. Based on proportional means, the adolescents with a history of abortion, practiced interpersonal support $(M=2.85)$ most frequently and health responsibility $(M=1.97)$ and exercise $(M=1.97)$ least frequently; the never- pregnant adolescents practiced self-actualization $(M=3.02)$ most frequently and exercise $(M=2.05)$ least frequently.

Hendricks, Murdaugh, Tavakoli, and Hendricks [7] studied the health behaviors in a sample of $10367^{\text {th }}$ and $8^{\text {th }}$ graders using the HPLP. Independent t-tests revealed that there were no statistically significant gender differences on the total HPLP. Based on subscale analysis, Hendricks reported proportional means indicating that the students practiced self-actualization health behaviors most $(M=3.03)$ and health responsibility health behaviors least $(M=2.02)$. For girls $(\mathrm{n}=524)$, self-actualization $(M=3.05)$ was practiced most and health responsibility was practiced least $(M=1.98)$. For boys $(\mathrm{n}=502)$, selfactualization $(M=3.00)$ was practiced most and health responsibility was practiced least $(M=2.06)$. As compared to adolescent boys, adolescent girls had statistically significant lower levels of health practices on the health responsibility $(t=-2.60, p=.04)$, exercise $(t=-$ $4.63, p=.01)$, and nutrition ( $t=-2.41, p=.02)$ subscales and a higher level on interpersonal support $(t=4.38, p=.01)$.

Haddad, Kane, Rajacich, Cameron, and Al-Ma'aitah [8] compared the health practices of 41 Canadian (average age 21 years) and 44 Jordanian (average 19 years) female nursing students using the HPLPII. Haddad et al. reported proportional means for the subscales as follows: for the Canadian students, the rank order noted was interpersonal relations (3.12), spiritual growth (2.97), nutrition (2.58), stress management (2.46), physical activity (2.42), and health responsibility (2.37); for the Jordanian students, the rank order noted was spiritual growth (2.98), interpersonal relations (2.78), stress management (2.58), nutrition (2.40), physical activity (2.12), and health responsibility (2.07). The Canadian students had statistically significant higher scores on interpersonal relations, health responsibility, and physical activity as compared to the Jordanian students.

In 2005, Callaghan investigated the health behaviors of a convenience sample 256 adolescents, aged 14 to 19 , using the HPLPII. Callaghan reported a mean of 131.54 for the total instrument. Based on averages for the subscales, spiritual growth $(M=26.71)$ was the health behavior practiced most and health responsibility $(M=17.76)$ practiced least by this sample of high school students.Descriptive statistics were not analyzed according to gender.

Using the HPLP-II, Smith and Bashore (2006) studied the health promotion behaviors of adolescent and young adult cancer survivors, aged 16 to $33(M=20.33 ; S D=4.02)$. Based on subscale analysis, proportional means indicated that spiritual growth $(M=3.04)$ was practiced most and health responsibility $(M=2.24)$ practiced least by this clinical sample.The proportional means for the remaining subscales were as follows in rank order: interpersonal relations (3.02), stress management (2.42), physical activity (2.38), and nutrition (2.26). Smith and Bashore stated that there were no statistically significant differences on the total HPLP-II and its subscales according to gender and age, but the actual results were not reported.

Several studies have used the ALP to assess adolescent healthpromoting lifestyle. Sapp [9] studied the health behaviors of 99 adolescents diagnosed with asthma, aged 12 to 17, using the ALP. Sapp reported descriptive statistics for the total ALP (Proportional
$M=2.69 ; S D=.40$ ). Sapp did not report descriptive statistics for the subscales of the ALP, nor did she analyze the data according to gender.

Hendricks and Hendricks [10] studied the health-promoting behaviors in a sample of 168 student athletes, aged 18 to $26(M=20$ years), attending historically Black colleges and universities. The researchers used the original ALP and reported a mean of 127.69 and standard deviation of 16.37 for the total ALP; subscale analysis of the ALP was not reported for this sample. Hendricks, Murdaugh, and Pender [11] factor analyzed the ALP in a sample of 2007 early adolescents, aged 10 to 15 . Results yielded 6 factors (a) health responsibility $(M=16)$, (b) physical activity $(M=17),(\mathrm{c})$ nutrition $(M=22)$, (d)personal growth $(M=23)$, (e) interpersonal relations $(M=21)$, and (f) stress management $(M=19)$; thus, the health responsibility subscale yielded the lowest score. The mean for the total ALP was $117(S D=19)$; however, data were not analyzed according to gender.

In summary, researchers have used the HPLP, the HPLPII, and the ALP to study health promoting lifestyles in a variety of adolescent and young adult samples. Across instruments and samples, proportional means suggest that self-actualization, spiritual growth, and personal growth tend to be the health behaviors most frequently reported, while health responsibility health behaviors tend to be the least frequently reported by adolescents and young adult samples in the United States and abroad. The available literature suggests that there is limited information on adolescent health promoting lifestyle behaviors using the ALP-R2 instrument and its subscales. Also, Hendricks et al. [7] and Smith and Bashore [12] found no gender differences on healthpromoting behaviors when total scores on the instrument (HPLP or HPLPII) were examined. This leaves open to question whether adolescent boys and girls differ on the practice of health behaviors on the ALP-R2. It is the intent of this study to provide this information using a sample of middle adolescent boys and girls, aged 15 to 17 to add to the knowledge base of the Health-Promotion Model [13].

\section{Research Questions}

1. Do adolescent boys and girls differ on their overall practice of health-promoting behaviors on the ALP-R2?

2. Do adolescent boys and girls differ on their practice of healthpromoting behaviors on the subscales of the ALP-R2?

3. What are the most frequently and least frequently practiced individual health behaviors on the ALP-R2 by adolescent boys and girls?

\section{Design}

This descriptive-comparative study is part of a larger research project on health-related outcomes in adolescents. The study focuses on a detailed analysis of one instrument used in the study, the ALP-R2.

\section{Methods}

The inclusion criteria for the sample wasmiddle adolescents, who were chronologically defined as ages 15-17 [14], and who were currently enrolled in an urban school system in northern New Jersey. The students had to be mentally and physically able to complete the study instruments. To minimize errors in measurement, only students who were able to read and comprehend the English language, as evaluated by the teacher and conveyed to the researcher, were 
included in the study. After the study was approved by the University Institutional Review Board, access was granted to a large urban high school in New Jersey. To obtain a sample of middle adolescents, students in grades 10 to 12 were approached by the researcher two weeks prior to administering the study materials. The researcher met with students in the health classes to explain the purpose of the study, the procedures, the rights of human subjects, and the need for student and one parent or guardian to consent for student participation. Students were given packets to take home to their parents/guardians that included a letter explaining the study, contact information for the researcher, and parental consent forms to be returned to teachers prior to the testing date. One week later, the researcher went to the designated classes to administer the instrument packets that included the ALP-R2 and a demographic data sheet. Of the 355 middle adolescents approached, 311 consented, met the criteria for inclusion, and completed the study packets.

\section{Adolescent Lifestyle Profile- R2}

The Adolescent Lifestyle Profile, originally developed by Hendricks, Pender, and Hendricks [1], is currently a 44-item selfreport instrument (ALP-R2) designed to measure the frequency of health-promoting behaviors in adolescents in seven domains, (a) health responsibility, (b) physical activity, (c) nutrition, (d) positive life perspective, (c) interpersonal relations, (d) stress management, and (e) spiritual health, according to C. S. Hendricks (personal communication, January 26, 2012). The summated scale uses a 4-point response format from $\mathrm{N}$ (never) to A (always). The possible range of scores for the total scale is 44 to 176; the higher the score on the instrument, the more frequent the health-promoting behavior.

Relative to content validity, Hendricks, Murdaugh, and Pender [11] stated that items on the ALP were originally developed from the HPLP II. Hendricks et al. established construct by correlating scores on the total ALP with scores on scales measuring hope $(r=.60, p=.001)$,, self-efficacy $(r=.47, p=.001)$, and self-esteem $(r=.35, p=.001)$ in a sample of 207 early adolescents, aged 10 to 15 . Hendricks et al. then factor analyzed the ALP using principal components and varimax and promax rotations. Results indicated a six-factor solution (a) personal growth, (b) health responsibility, (c) nutrition, (d) physical activity, (e) interpersonal relations, and (f) stress management. To avoid cross loading of items on factors, Hendricks et al. revised the scale and reworded some of the items. Further, the personal growth subscale was renamed as positive life perspective, and a subscale labeled spiritual health was added from items on the personal growth subscale. This resulted in a 44-item scale with 7 subscales: (a) health responsibility, (b) physical activity, (c) nutrition, (d) positive life perspective, (e) interpersonal relations, (f) stress management, and (g) spiritual health. C. S. Hendricks (personal communication, January 26, 2012) reported that a principal axis factor analysis of the 44-item,now labeled ALP-R2, supported the seven factors used as subscales in the instrument.

The coefficient alpha reliabilities in this study for adolescent boys (B) and girls $(\mathrm{G})$ on the subscales of the ALP-R2 were: Health Responsibility (.73B, .70G), Physical Activity (.78B, .78G), Nutrition (.66B, .68G), Positive Life Perspective $(.73 \mathrm{~B}, .65 \mathrm{G})$, Interpersonal Relations $(.65 \mathrm{~B}, .61 \mathrm{G})$, Stress Management $(.73 \mathrm{~B}, .61 \mathrm{G})$, and Spiritual Health $(.84 \mathrm{~B}, .89 \mathrm{G})$. The coefficient alpha for the total ALP-R2 for the entire sample was .91 .

\section{Data analysis}

Data were analyzed using descriptive statistics and SPSS version 20. Descriptive statistics for the ALP-R2 were assessed for the total sample and adolescentboys and girls separately. An independent t-test was performed to determine gender differences on the total ALP-R2. Means were generated for each subscale on the ALP-R2 for the total sample and for adolescent boys and girls separately. An independent $\mathrm{t}$-test was performed to determine gender differences on the subscales of the ALP-R2. Because each subscale has a different number of items, proportional means were then calculated by dividing the mean for the subscale by the number of items on the subscale and then ranking the order of the most and least health practices of the participants according to the subscale. The frequency of use of the 44 items on the ALP-R2 was also examined by obtaining a proportional mean for each item. The five highest and the five lowest proportional means are reported for adolescent boys and girls separately, along with rank position of the items.

\section{Sample Demographic Data}

A cohort of 355 students in an urban high school were approached to participate in the study. The final sample of convenience consisted of the 311 participants, of whom 163 were adolescent males, and 148 were adolescent females. Their ages ranged from 15 to 17 ( $M=16.1$, $S D=1.66$ ), and they were sophomores, juniors, and seniors in high school. Relative to ethnicity, $12.5 \%$ were White, $17.4 \%$ were Black, 8.3\% were Asian, $54.4 \%$ were Latino, and $7.4 \%$ reported "Other". Only 19 students reported having a medical condition, such as diabetes or asthma.

\section{Results}

Relative to research question number 1 , descriptive statistics are reported for the ALP-R2 in Table 1 for the total sample and adolescent boys and girls separately. An independent t-test determined that adolescent boys $(M=121.02)$ had a higher mean score on the total ALP-R2 than adolescent girls $(M=114.99)$ at a statistically significant level $(t(308)=2.57, p=.01$; Table 1$)$.

\begin{tabular}{|l|l|l|l|}
\hline Total Scale & Range & Mean & SD \\
\hline Total Sample & $59-173$ & 118.08 & 20.80 \\
\hline Males & $64-173$ & 121.02 & 20.37 \\
\hline Females & $59-162$ & 114.99 & 20.91 \\
\hline
\end{tabular}

Table 1: Descriptive Statistics for ALP-R2 for total sample $(\mathrm{N}=311)$ and males $(\mathrm{N}=161)$ and females $(\mathrm{N}=150)$.

Relative to research question number 2, means, proportional means, and ranks for the ALP-R2 subscales for the total sample and adolescent boys and girls separately are presented in Table 2 . Independent t-tests revealed statistically significant gender differences on four subscales whereby adolescent boys had higher mean scores than adolescent girls: physical activity $(t(309)=4.20, p=.001)$, nutrition $(t(309)$ $=2.04, p=.04)$, positive life perspective $(t(309)=1.95, p=.05)$, and stress management $(t(309)=3.29, p=.001)$. According to the proportional means and ranks for the ALP-R2 subscales, adolescent boys practiced positive life perspective health behaviors most frequently and spiritual health behaviors least frequently. In contrast, adolescent girls practiced interpersonal relations health behaviors most frequently and health responsibility behaviors least frequently. 
Citation: Scoloveno R (2017) Gender Differences in Health Practices in Middle Adolescent Boys and Girls. Int J Nurs Clin Pract 4: 268. doi: https://doi. org/10.15344/2394-4978/2017/268

Page 4 of 8

\begin{tabular}{|c|c|c|c|c|c|c|}
\hline Subscales & Means & SD & $\begin{array}{l}\text { Proportional } \\
\text { Means }\end{array}$ & Rank & $\mathrm{t}$ & $\mathrm{p}$ \\
\hline \multicolumn{7}{|c|}{ Health Responsibility } \\
\hline Total & 15.64 & 4.05 & 2.23 & 6 & & \\
\hline Males & 16.02 & 3.99 & 2.29 & 6 & 1.46 & .10 \\
\hline Females & 15.27 & 4.08 & 2.18 & 7 & & \\
\hline \multicolumn{7}{|c|}{ Physical Activity } \\
\hline Total & 16.52 & 4.18 & 2.75 & 4 & & \\
\hline Males & 17.45 & 3.91 & 2.91 & 4 & 4.20 & .001 \\
\hline Females & 15.51 & 4.26 & 2.58 & 4 & & \\
\hline \multicolumn{7}{|l|}{ Nutrition } \\
\hline Total & 17.94 & 3.73 & 2.58 & 5 & & \\
\hline Males & 18.37 & 3.42 & 2.62 & 5 & 2.04 & .04 \\
\hline Females & 17.51 & 3.98 & 2.50 & 5 & & \\
\hline \multicolumn{7}{|c|}{ Positive Life Perspective } \\
\hline Total & 18.96 & 3.98 & 3.16 & 1 & & \\
\hline Males & 19.45 & 3.89 & 3.08 & 1 & 1.95 & .05 \\
\hline Females & 18.40 & 4.02 & 2.94 & 2 & & \\
\hline \multicolumn{7}{|c|}{ Interpersonal Relations } \\
\hline Total & 18.11 & 3.23 & 3.04 & 2 & & \\
\hline Males & 17.88 & 3.20 & 2.98 & 3 & -1.30 & .19 \\
\hline Females & 18.36 & 3.27 & 3.06 & 1 & & \\
\hline \multicolumn{7}{|c|}{ Stress Management } \\
\hline Total & 17.42 & 3.41 & 2.90 & 3 & & \\
\hline Males & 18.03 & 3.42 & 3.01 & 2 & 3.29 & .001 \\
\hline Females & 16.78 & 3.28 & 2.80 & 3 & & \\
\hline \multicolumn{7}{|c|}{ Spiritual Health } \\
\hline Total & 13.24 & 4.76 & 2.21 & 7 & & \\
\hline Males & 13.33 & 4.39 & 2.22 & 7 & .31 & .76 \\
\hline Females & 13.16 & 5.15 & 2.19 & 6 & & \\
\hline
\end{tabular}

Table 2: Means, Proportional Means, and Ranks for ALP-R2 Subscales

for total sample $(\mathrm{N}=311)$, Males $(\mathrm{N}=161)$, and Females $(\mathrm{N}=150)$.

Relative to research question number 3, proportional means and ranks for the five most and 5 least practiced health behavior items from the ALP-R2 are presented in Table 3 for adolescent boys and girls separately. For adolescent boys, the most frequently practiced health behavior was from the nutrition subscale and involved "eating a variety of proteins." The least frequently practiced health behavior was from the spiritual health subscale and involved "sharing spiritual beliefs." For adolescent girls, the most frequently practiced health behavior was from the nutrition subscale and involved "eating a variety of proteins." The least frequently practiced health behavior was from the health responsibility subscale and involved "attending programs about preventing health problems and improving health." Notably, four of the five least frequently practiced health behaviors by girls were from the health responsibility subscale, whereas only two of the five least frequently practiced health behaviors by boys were from the health responsibility subscale.

\section{Discussion}

The mean score $(M=118.08)$ obtained on the total ALP-R2 with the present sample of middle adolescents was comparable

\begin{tabular}{|c|c|c|c|c|}
\hline Item Number & & Subscale & Mean & Rank \\
\hline \multicolumn{5}{|l|}{ Males } \\
\hline & \multicolumn{4}{|c|}{ Most Frequent } \\
\hline & \# 30 & Nutrition & 3.46 & 1 \\
\hline & \# 39 & PLP1 & 3.35 & 2 \\
\hline & $\# 25$ & SM2 & 3.32 & 3 \\
\hline & $\# 23$ & PLP & 3.28 & 4 \\
\hline & \# 38 & PLP & 3.26 & 5 \\
\hline & \multicolumn{4}{|c|}{ Least Frequent } \\
\hline & $\# 34$ & HR3 & 2.13 & 40 \\
\hline & \# 41 & SH4 & 2.12 & 41 \\
\hline & $\# 35$ & SM & 2.06 & 42 \\
\hline & $\# 33$ & $\mathrm{HR}$ & 2.03 & 43 \\
\hline & $\# 20$ & $\mathrm{SH}$ & 1.90 & 44 \\
\hline \multicolumn{5}{|l|}{ Females } \\
\hline & \multicolumn{4}{|c|}{ Most Frequent } \\
\hline & \# 30 & Nutrition & 3.41 & 1 \\
\hline & \# 39 & PLP & 3.39 & 2 \\
\hline & \# 6 & IR5 & 3.23 & 3 \\
\hline & $\# 12$ & IR & 3.19 & 4 \\
\hline & $\# 38$ & PLP & 3.13 & 5 \\
\hline & \multicolumn{4}{|c|}{ Least Frequent } \\
\hline & \# 33 & HR & 2.00 & 40 \\
\hline & \# 34 & HR & 1.97 & 41 \\
\hline & $\# 8$ & $\mathrm{HR}$ & 1.92 & 42 \\
\hline & $\# 20$ & $\mathrm{SH}$ & 1.90 & 43 \\
\hline & $\# 22$ & HR & 1.43 & 44 \\
\hline
\end{tabular}

Table 3: Proportional Means and Ranks of 5 most and 5 least practiced health behavior items.

From the ALP-R2 for Males $(N=161)$ and Females $(N=150)$

Note: 1. Positive Life Perspective, 2. Stress Management, 3. Health

Responsibility,

4. Spirital Health, 5. Interpersonal Relations

to that $(M=117)$ reported by Hendricks et al. [11] for a sample of early adolescents using the original ALP, but lower than that $(M=127.69)$ reported by Hendricks and Hendricks [10] for a sample of Black adolescents, aged 18 to 26, using the ALP. Based on these means obtained on the ALP and ALP-R2 across studies, it would be tempting to suggest that adolescents practice more health behaviors as they grow older, but only longitudinal data can determine if this in fact is so.

With respect to the first research question, adolescent girls were found to practice less health-promoting lifestyle behaviors than did adolescent boys. This is the first study to have examined gender differences on the ALP-R2, so a comparison across previous studies is not possible. The findings, however, support Pender's [13] proposition that there are gender differences in health-promoting behaviors. Clearly, more studies are needed that examine gender differences in adolescent health promoting behaviors so that it can be determined whether girls or boys performhigher levels of health-promoting lifestyle behaviors on the ALP-R2. Of note, however, is that means obtained on health-promoting instruments for total samples do 
not provide us with this important information so researchers need to report descriptive statistics for boys and girls separately when studying health behaviors.

Relative to the second research question, adolescent boys reported higher levels of health behaviors on four of the seven subscales of the ALP-R2 than adolescent girls at a statistically significant level. Adolescent boys were more apt to be physically active, follow good dietary practices, have a positive attitude toward the future and setting goals, and better manage their stress by getting adequate sleep and relaxation. Adolescent girls need to be counseled to improve their performance on these health behaviors so that they might reap the same benefits of these health behaviors as their male counterparts.

According to the proportional means for the subscales, the rank order for adolescent boys was as follows: positive life perspective, stress management, interpersonal relations, physical activity, nutrition, health responsibility, and spiritual health. The rank order for adolescent girls was as follows: interpersonal relations, positive life perspective, stress management, physical activity, nutrition, spiritual health, and health responsibility. Health responsibility, a subscale of HPLP, HPLPII, ALP, and ALP-R2 tends to be the least practiced health behavior across studies using these instruments with adolescents $[6-12,15]$. The current findings for adolescent boys and girls are consistent with the previous findings. The subscale of health responsibility assesses the extent to which individuals seek out health information from nurses, doctors, school counselors, articles, and programs and the extent to which they avoid risk behaviors, such as smoking, drinking, and drugs. These accrued findings strongly suggest that health education needs to be made more effective and appealing to adolescent boys and girls and that professionals need to be more readily accessible, available, and acceptable to this age group for health-related information.

Another area of concern with the findings for the second research question is that physical activity and nutrition were ranked lower than subscales that assessed psychological concerns, such as interpersonal relations, for both adolescent boys and girls. This finding tend to be consistent with previous adolescent studies reporting health behaviors on the HPLP, HPLPII, and ALP [6-10,12,15]. Given that physical activity and good nutrition are essential elements to prevent chronic diseases and obesity [16], improving physical activity and good nutrition among adolescent boys and girls is definitely warranted in terms of a health-promoting lifestyle.

Relative to the third research question, interesting findings were found on individual items of the ALP-R2 for both adolescent boys and girls. Eating a variety of proteins, an item on the nutrition subscale, was the most frequently practiced health promoting lifestyle behavior for both adolescent boys and girls. Unfortunately, there is no way of knowing whether this health practice involved eating proteins at "fast food" chains or eating nutritiously-prepared proteins at home. This concern merits future investigation so that we have a better understanding of why this health behavior emerged as number one for adolescent boys and girls. For adolescent boys, the least frequently health behavior was relative to the subscale of spiritual health, which involves sharing their spiritual beliefs. For adolescent girls, the least frequently reported health behavior was relative to the subscale of health responsibility and concerned attending health programs to learn about preventing health problems and improving their health These findings are consistent with psychosocial developmental theory during middle adolescence, which suggested that during this phase of development adolescents tend to rebel against all authority [17]. That is, adolescent boys tend to eschew "higher authority," whereas adolescent girls tend to avoid the authority of health professionals. The finding for boys warrants less immediate attention than the finding for girls.

\section{Relevance to Clinical Practice}

Based on the findings of this study, adolescent girls practiced fewer health-promoting behaviors than adolescent boys, making them a vulnerable population. To complicate matters, when all the individual items on the ALP-R2 were examined, adolescent girls least practiced health responsibility, which would keep them more, informed about good health practices. Adolescent girls avoid seeking guidance and asking questions of doctors and nurses, and thus are a challenge to health care professionals who provide care to this age group. Clearly, outreach measures by healthcare professionals, especially schoolnurses and physicians, are needed and might best be practiced in school settings that are less threatening environments than offices or clinics. One outreach measure could be a health fair about healthpromoting lifestyles in the school setting whereby inducements for attendance, such as skin care products, are geared more toward girls than toward boys.

As noted earlier, performing physical activity and good nutrition are two areas of concern for both middle adolescent boys and girls. School nurses and physicians, working with physical education teachers in the high school, need to develop strategies to increase physical activity for this age group. Walking is a safe and highly recommended strategy to increase physical activity [16], among adolescents. Because of the developmental phase of adolescence is marked by idealism [18], getting middle adolescent boys and girls to participate in walk-a-thons for a good cause is one way of increasing their physical activity. Over time, their participation in walking for good causes may become incorporated as a physical activity in their health-promoting lifestyle.

With respect to promoting good nutrition among middle adolescent boys and girls, school nurses and physicians, and other healthcare professionals need to capitalize on the recommendation that schools are in a unique position to foster healthy eating habits [16]. First and foremost, health care professionals, including nurses and doctors, need to take the leadership in addressing better culturally relevant nutrition among adolescents. Healthcare professionals, specifically school nurses, can work with teachers to put into place comprehensive and grade-related health education curricula whereby students learn about health eating behaviors. Schools also need to put into practice the serving of nutritious and appealing food and beverages in school cafeterias, vending machines, and other venues that offer meals to students. Secondly, to ensure that the healthy eating behaviors learned by students in school are carried over in the home environment, parent-nurse meetings analogous to parent-teacher meetings need to be conducted by school nurses along with other interested healthcare professionals who are willing to volunteer their time.

\section{Limitations}

The results of this study are limited to a sample of convenience of middle adolescent high school students living in an urban area in a Middle Atlantic state, a majority of whom were of Latino heritage. Based on the socio-demographic variables in Pender's model [13], 
Citation: Scoloveno R (2017) Gender Differences in Health Practices in Middle Adolescent Boys and Girls. Int J Nurs Clin Pract 4: 268. doi: https://oi. org/10.15344/2394-4978/2017/268

Page 6 of 8

the findings of this study would likely vary according to geographic location and ethnic backgrounds of the students as well as stage of adolescence. Because the number of adolescent males and females in the study was relatively comparable, non-equivalent sample sizes were not a problem in the analysis.

\section{Conclusions}

Gender was an important socio-demographic variable in Pender's Health Promotion Model [13] among middle adolescents attending high school in this study. In general, adolescent boys practiced more health-promoting lifestyle behaviors than didadolescent girls, and there were significant differences in domain-specific health behaviors, such as physical activity, nutrition, positive life perspective and stress management, whereby boys had higher levels than girls. When considering the specific domains of health-promoting lifestyle behaviors, there were variations in the rank ordering of health behaviors practiced more and less frequently by adolescent boys and girls. The only commonality in health behaviors practiced by adolescent boys and girls was that the most frequent health behavior practiced by both of them was eating a variety of proteins. More descriptive studies of gender differences in health-promoting lifestyles are needed to strengthen the knowledge base about health practices in adolescents.

\section{Impact Statement}

\section{What does this paper contribute to the wider global clinical community?}

- School nurses and physicians, and other healthcare professionals can capitalize on the recommendation that schools are in a unique position to foster healthy eating habits.

- Health care professionals, including nurses and doctors, need to take the leadership in addressing better culturally relevant nutrition among adolescents.

- Healthcare professionals, specifically school nurses, can work with teachers to put into place comprehensive and grade-related health education curricula whereby students learn about healthy eating behaviors.

\section{Competing Interests}

The author declears that he has no competing interest exists.

\section{References}

1. Hendricks C, Pender N, Hendricks DL (2001) The Adolescent Lifestyle Profile (ALP-R2). Copyrighted with the National Library of Congress.

2. Pender N (1982) Health promotion in nursing practice.New York: AppletonCentury-Croft.

3. Pender NJ, Murdaugh C, Parsons MA (2010) Health promotion in nursing practice (6th ed.). Upper Saddle River, NJ: Pearson/Prentice-Hall.

4. Walker S, Sechrist K, Pender N (1987) The Health-Promoting Lifestyle Profile: Development and psychometric characteristics. Nurs Res 36: 7681.

5. Walker S, Hill-Polerecky D (1996) Evolution and evaluation of Health Promoting Lifestyle Profile II. Unpublished manuscript.

6. Felton GM, Parsons MA, Hassell JS (1998) Health behavior and related factors in adolescents with a history of abortion and never-pregnant adolescents. Health Care Women Int 19: 37-47.
7. Hendricks CS, Murdaugh C, Tavakoli A, Hendricks DL (2000) Health promoting behaviors among rural southern early adolescents. ABNF J 11: 123-128.

8. Haddad L, Kane D, Rajacich D, Cameron S, Al-Ma'aitah R (2004) A comparison of health practices of Canadian and Jordanian nursing students. Public Health Nurs 21: 85-90.

9. Sapp CJ (2003)Adolescents with asthma: Effects of personal characteristics and health promoting lifestyle behaviors on health related quality of life (Doctoral dissertation). Available from ProQuest Dissertations and Theses database. (UMI No. 3092071).

10. Hendricks DL, Hendricks CS (2005) The relationship of hope and selfefficacy to health-promoting behaviors among student-athletes attending historically Black colleges and universities. The Journal of Multicultural Nursing and Health 11: 23-34.

11. Hendricks C, Murdaugh C, Pender N (2006) The Adolescent Lifestyle Profile: Development and psychometric properties. J Natl Black Nurses Assoc 17: 1-5.

12. Smith $A B$, Bashore $L$ (2006) Ther effect of clinic-based health promotion education on perceived health status and health promotion behaviors of adolescent and young adult cancer survivors. J Pediatr Oncol Nurs 23: 326-334.

13. Pender N (1996) Health promotion in nursing practice ( $3^{\text {rd }}$ ed.). Stamford, CT: Appleton \& Lange.

14. Duncan PM, Shaw J (2007) Bright futures guidelines for health supervision of infants, children, and adolescents pocket guide (3rded). Evanston, II: American Academy of Pediatrics.

15. Callaghan DM (2005) The influence of spiritual growth on adolecents' initiative and responsibility for self-care. Pediatr Nurs 31: 91-115.

16. National Center for Chronic Disease Prevention and Health Promotion (2014) Division of Nutrition, Physical Activity and Obesity.

17. Burns CE, Brady MA, Dunn AM, Starr NB (2001) Pocket reference for pediatric primary care. Philadelphia: W.B. Saunders

18. Myers DJ (2013) Psychology. (10th ed.). New York, NY: Worth Publishers. 